\title{
Determining the effect of ellagic acid on the proliferation and migration of pancreatic cancer cell lines
}

\author{
Ji Yoon $\mathrm{Kim}^{1} \wedge$, Yun Ju Choi ${ }^{2}$, Ha-Jeong Kim ${ }^{2,3}$ \\ ${ }^{1}$ Department of Pediatrics, Kyungpook National University, School of Medicine, Daegu, South Korea; ${ }^{2}$ Department of Physiology, Kyungpook \\ National University, School of Medicine, Daegu, South Korea; ${ }^{3}$ BK21 Plus KNU Biomedical Convergence Program, Department of Biomedical \\ Science, Kyungpook National University, School of Medicine, Daegu, South Korea \\ Contributions: (I) Conception and design: JY Kim, HJ Kim; (II) Administrative support: None; (III) Provision of study materials or patients: YJ Choi, \\ HJ Kim; (IV) Collection and assembly of data: YJ Choi, HJ Kim; (V) Data analysis and interpretation: JY Kim, HJ Kim; (VI) Manuscript writing: All \\ authors; (VII) Final approval of manuscript: All authors. \\ Correspondence to: Ha-Jeong Kim. 680 Gukchaebosang-ro, Jung-gu, Daegu, South Korea. Email: kimhajeong@knu.ac.kr.
}

Background: Ellagic acid is a natural dietary compound found in several berries and fruits. It inhibits fibrosis, inflammation and carcinogenesis. We tried to find out what role ellagic acid plays in pancreatic cancer to see if it can be used as an adjuvant for chemotherapy.

Methods: Three pancreatic cancer cell lines, PANC-1, AsPC-1, and MIA PaCA-2, were used. Cell growth was measured by MTT assay. Activities of caspase- 3 and caspase- 8 , and caspase- 9 were evaluated to determine the apoptosis pathway. Epithelial to mesenchymal transition was identified through mRNA expression of associated genes, which were transforming growth factor-beta, matrix metalloproteinase-2 and matrix metalloproteinase-9. Quantitative real time PCR was used to verify mRNA expression. To determine the effect on migration, transwell system was used.

Results: Ellagic acid inhibits pancreatic cancer cell growth by stimulating apoptosis. Apoptosis induced by ellagic acid in pancreatic cancer cells, is mediated by the activation of caspase- 3 and caspase- 9 , and not caspase-8. Ellagic acid also suppresses migration via the inhibition of epithelial mesenchymal transition (EMT) in pancreatic cancer cells. Ellagic acid decreased the expression levels of transforming growth factorbeta, matrix metalloproteinase-2 and matrix metalloproteinase-9, while it increased that of E-cadherin.

Conclusions: These findings suggest that ellagic acid is useful in pancreatic cancer treatment.

Keywords: Ellagic acid; pancreatic cancer; proliferation; apoptosis; migration

Submitted Jul 01, 2020. Accepted for publication Oct 30, 2020.

doi: $10.21037 /$ tcr-20-2446

View this article at: http://dx.doi.org/10.21037/tcr-20-2446

\section{Introduction}

Ellagic acid (2,3,7,8-tetrahydroxy[1]-benzopyranol[5,4,3cde]benzopyran-5,10-dione) is a natural dietary polyphenolic compound found in several fruits, nuts, and plants, such as strawberries, raspberries, blackberries, grapes, walnuts, and green tea (1). Ellagic acid has multiple biological activities, such as antioxidant, anti-inflammatory and antifibrotic properties (2-4). Proinflammatory cytokines, such as IFN- $\gamma$, TNF- $\alpha$, and IL-1 (5-7), were suppressed and antiinflammatory cytokine, such as IL-10, was increased by ellagic acid. Ellagic acid also suppresses the expression of cyclooxygenase 2 and inducible nitric oxide synthase via

^ ORCID: Ji Yoon Kim, 0000-0002-5577-6629; Ha-Jeong Kim, 0000-0002-7341-7988. 
the inhibition of nuclear factor-kappa B (NF- $\mathrm{BB})$ activity in several normal and cancer cells $(8,9)$.

The anticancer effect of ellagic acid has also been reported in several types of cancers, including liver, skin, esophageal, colon, prostate, breast, and pancreatic cancer. The antiproliferative activity of ellagic acid on several tumor cell lines has been reported (3,10-14). Ellagic acid induces apoptosis by downregulation the expression of Bcl-2, that inhibits apoptosis, and upregulation of Bax, which functions as a proapoptotic factor $(15,16)$. In addition, ellagic acid inhibited the proliferation by downregulating cyclin D1 and cyclin E1, which required for the entry into and completion of $\mathrm{S}$ phase and leaded to the arrest in the G1 phase of the cell cycle (17). However, the mechanisms mediating the anticancer effect of ellagic acid are still unclear.

Pancreatic cancer has an extremely poor prognosis, with a 5-year survival rate of less than 5\% (18). Most patients with pancreatic cancer die from distant metastasis (19). Tumor metastasis is a complex process. First, cancer cells grow in the primary site with avoiding apoptosis process. Second, cancer cells migrate into and invade the extracellular matrix and intravasate into the blood or lymphatic vessel. It is believed that epithelial mesenchymal transition (EMT) of cancer cells is needed in this step. Then, tumor cells must survive in the bloodstream with avoiding anoikis. Next, metastatic cells extravasate into and colonize the metastatic site (20). Most anticancer agents promote apoptosis and suppress the migration and invasion of tumor cells. Pancreatic cancer has a poor response to conventional chemotherapy and radiotherapy (21).

In this study, we aimed to determine the effect of ellagic acid on the proliferation and migration of pancreatic cancer cells. We present the following article in accordance with the MDAR checklist (available at http://dx.doi. org/10.21037/tcr-20-2446).

\section{Methods}

\section{Cells}

PANC-1, AsPC-1 and MIA PaCA-2 were obtained from Byungheon Lee in Kyungpook National University, School of Medicine. PANC-1 and MIA PaCA-2 were maintained in Dulbecco's Modified Eagle medium containing penicillin and streptomycin (100 units/mL) and $10 \% \mathrm{FBS}$ at $37^{\circ} \mathrm{C}$ in a $5 \% \mathrm{CO}_{2}$ incubator. AsPC-1 was maintained in RPMI media, containing penicillin and streptomycin (100 units/mL) and $10 \% \mathrm{FBS}$ at in $37{ }^{\circ} \mathrm{C}$ in $5 \% \mathrm{CO} 2$ incubator. The study was conducted in accordance with the Declaration of Helsinki (as revised in 2013).

\section{MTT assay}

Ellagic acid was obtained from Sigma (E2250), and reconstituted with $1 \mathrm{M} \mathrm{NaOH}$ at $10 \mathrm{mg} / \mathrm{mL}$ concentration. 0 to $1,000 \mathrm{mM}$ was used after diluted with culture media. Tetrazolium 3-(4,5-dimethylthiazolyl-2)-2,5diphenyltetrazolium bromide (MTT) buffer was purchased from Sigma (CT02). $5 \times 10^{4} /$ well cells were plated on 96 well plates with the indicated concentration of ellagic acid and incubated for $72 \mathrm{~h}$ at $37^{\circ} \mathrm{C}$. Cell growth was assayed every $24 \mathrm{~h}$, using MTT solution. Then, $10 \mu \mathrm{L}$ of MTT buffer was added and incubated for $2 \mathrm{~h}$ at $37^{\circ} \mathrm{C} .100 \mu \mathrm{L}$ of dimethyl sulfoxide (DMSO) solution was added and the cells were incubated for $10 \mathrm{~min}$ at room temperature in dark conditions. Absorbance at $550 \mathrm{~nm}$ was measured. To test the effect of Interferon-gamma (IFN- $\gamma$ ), from R\&D systems (285-IF-100), $0.5 \mathrm{ng} / \mathrm{mL}$ of IFN- $\gamma$ was treated $16 \mathrm{~h}$ prior to ellagic acid treatment. Each experiment was performed in triplicate.

\section{Caspase activity assay}

$5 \times 10^{4} /$ well cells were plated on 96 well black plates with the indicated concentration of ellagic acid and incubated for $48 \mathrm{~h}$ at $37{ }^{\circ} \mathrm{C}$. Caspase- 3 , caspase- 8 , and caspase- 9 activities were determined using caspase multiplex kit from Abcam (ab219915) following the manufacture's protocol. SpectraMax (Molecular Devices) was used to detect fluorescence. Activity was expressed as the fold increase in cells before ellagic acid treatment. Each experiment was performed in duplicate.

\section{Quantitative real time PCR}

Total RNA was isolated from cells using an RNA extraction kit (Takara Bio, 9769A). cDNA was synthesized from $1 \mu \mathrm{g}$ of total RNA using a cDNA synthesis kit (Takara Bio, 6100A) following the manufacturer's protocol. The primer pair sequences used were presented in Table 1. Quantitative realtime PCR was performed using SYBR Premix Ex Taq from Takara Bio (RR820A). Data were presented as fold changes in mRNA expression relative to GAPDH expression. 
Table 1 Primers list

\begin{tabular}{lll}
\hline Gene & Forward & Reverse \\
\hline TGF- $\beta$ & 5'-CACTCCCGTGGCTTCTAGTG-3' & 5'-CTGGCGAGCCTTAGTTTGGA-3' \\
E-cadherin & 5'-GTCTGTAGGAAGGCACAGCC-3' & 5'-TGCAACGTCGTTACGAGTCA-3' \\
MMP-2 & 5'-CAAGGACCGGTTTATTTGGC-3' & 5'-ATTCCCTGCGAAGAACACAGC-3' \\
MMP-9 & 5'-TTGACAGCGACAAGAAGTGG-3' & 5'-GCCATTCACGTCGTCCTTAT-3' \\
GAPDH & 5'-TCACCACCATGGAGAAGGC-3' & 5'-GCTAAGCAGTTGGTGGTGCA-3' \\
\hline
\end{tabular}
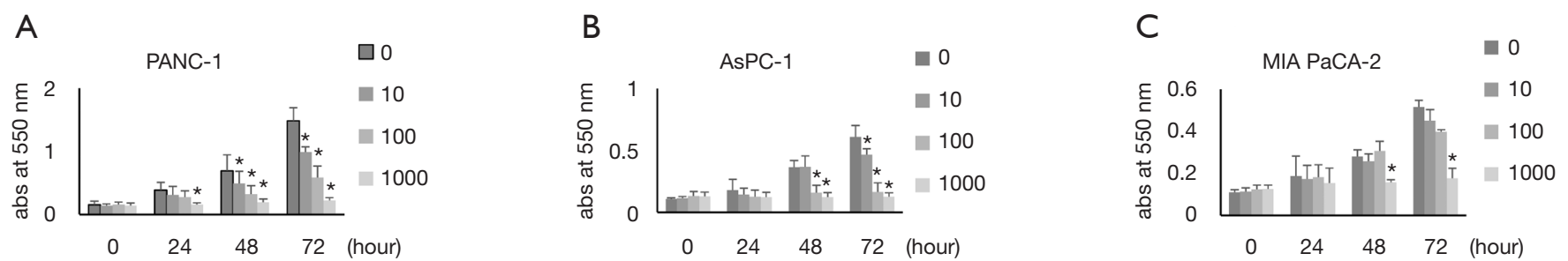

Figure 1 Ellagic acid inhibits pancreatic cancer cell proliferation. (A) PANC-1, (B) AsPC-1, (C) MIA PaCA-2. Cells were plated on microplates with ellagic acid and incubated in indicated times. 0 to 1,000 $\mu$ M ellagic acid were treated on each cell. MTT assay was performed as described in Materials and Methods. Data are presented as mean \pm SD from three individual experiments. * $\mathrm{P}<0.05$ compared with $0 \mu \mathrm{M}$ ellagic acid treated group at each time.

\section{Enzymes-linked immunosorbent assay (ELISA)}

The concentrations of TGF- $\beta$ (R\&D System, DB250), MMP-2 (R\&D System, DMP2F0), and MMP-9 (R\&D System, DMP900) in the culture supernatant were measured using an enzyme linked immunosorbent assay kit following the manufacture's protocol.

\section{Migration assay}

$5 \times 10^{4}$ cells were suspended in media containing $5 \%$ FBS and were plated in the upper chamber of Transwell $(8-\mu \mathrm{m}$ pore size; Corning, Costar) in 24-well plates. A medium containing $10 \%$ FBS was added to the lower chamber. The indicated concentration of ellagic acid was added to both chambers. Migrated cells on the Transwell membrane were fixed after $16 \mathrm{~h}$ of incubation. Cells were stained with crystal violet, and the numbers were calculated using MacBiophotonics Image J software.

\section{Statistical analysis}

The results were presented as mean \pm S.D. from at least three independent experiments. All statistical analyses were performed using the paired $t$-test. Data were considered significant if the $\mathrm{P}<0.05$.

\section{Results}

\section{Effect of ellagic acid on the growth of pancreatic cancer cell lines}

To evaluate the effect of ellagic acid on pancreatic cancer, three different cell lines, PANC-1, AsPC-1 and MIA $\mathrm{PaCA}-2$, were used. Cell growth in presence of 10 to $1,000 \mu \mathrm{M}$ of ellagic acid was performed every $24 \mathrm{~h}$ for $72 \mathrm{~h}$ by MTT assay. Ellagic acid inhibited the proliferation of all three cell lines (Figure 1). However, the inhibitory concentration varied depending on cell types. Proliferation of PANC-1 was inhibited after adding $10 \mu \mathrm{M}$ of ellagic acid, and its inhibition was dose dependent. AsPC-1 proliferation was inhibited after adding $100 \mu \mathrm{M}$ of ellagic acid, while MIA-PaCA-2 proliferation was only prohibited after adding $1,000 \mu \mathrm{M}$ of ellagic acid

The inhibitory effect of ellagic acid after IFN- $\gamma$ treatment was examined. IFN- $\gamma$ inhibited the expression of pancreatic cancer cells $16 \mathrm{~h}$ prior to ellagic acid treatment, while IFN- $\gamma$ inhibited the growth of all types of pancreatic 
A

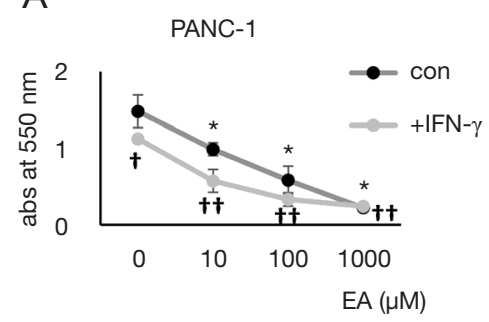

B

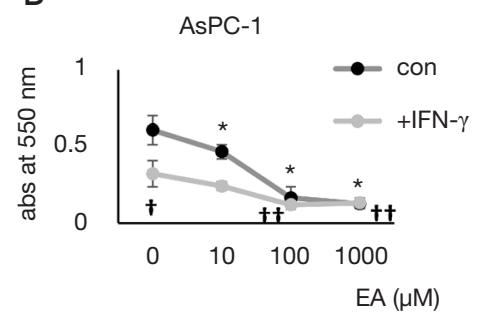

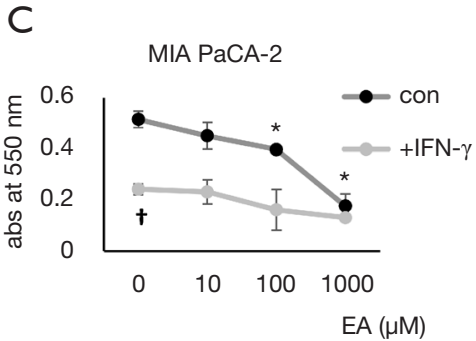

Figure 2 IFN- $\gamma$ inhibits pancreatic cancer cell proliferation. (A) PANC-1, (B) AsPC-1 and (C) MIA PaCA-2. The cells were plated on microplates with ellagic acid and incubated at $48 \mathrm{~h}$. Next, 0 to 1,000 $\mu \mathrm{M}$ ellagic acid were added to each cell. MTT assay was performed as described in the Materials and Methods. Data are presented as mean $\pm \mathrm{SD}$ from three individual experiments. *, $\mathrm{P}<0.05$ compared with 0 h; ${ }^{\dagger}$, $\mathrm{P}<0.05 ;{ }^{\dagger \dagger}, \mathrm{P}<0.01$ compared with control group and IFN- $\gamma$ treatment group.

cancer cells. Ellagic acid further inhibited the growth of PANC-1 and AsPC-1 cells in dose-dependent manner. Further inhibitory effects of ellagic acid were not observed in MIA PaCA-2 cells (Figure 2).

\section{Effect of ellagic acid on caspase-3 and caspase-9 activity in pancreatic cancer cells}

Caspase-3, caspase-8, and caspase-9 activities were measured using a multiplex activity assay kit as described in Materials and Methods. Pancreatic cells were treated with IFN- $\gamma$ and ellagic acid for $48 \mathrm{~h}$. The caspase- 3 and caspase- 9 activities increased after treatment with ellagic acid in a dose-dependent manner; however, the caspase- 8 activity in PANC-1 cells and AsPC-1 cells remained unchanged. IFN- $\gamma$ did not affect the caspase activity in PANC-1 cells but affected that in AsPC-1 cells (Figure $3 A, B, C, D, E, F$ ). The caspase- 3 , caspase- 8 , and caspase- 9 activities in MIA PaCA-2 cells remained unchanged after ellagic acid treatment without IFN- $\gamma$ treatment. After IFN- $\gamma$ treatment, only caspase- 3 activity was increased dose-dependently by ellagic acid (Figure 3G,H,I).

\section{Ellagic acid promoting migration and EMT in pancreatic cancer cells}

TGF- $\beta$ and E-cadherin mRNA expression was examined by q-PCR. TGF- $\beta$ expression was inhibited, and E-cadherin expression was increased by ellagic acid in PANC- 1 and AsPC-1 cells in a dose- and time-dependent manner (Figure $4 A, B, C, D)$. TGF- $\beta$ and $\mathrm{E}$-cadherin expression in MIA PaCA-2 cells was remained unchanged by ellagic acid
(Figure 4E,F).

MMP-2 and MMP-9 mRNA expression was also evaluated. Both MMP-2 and MMP-9 expression was inhibited by ellagic acid in PANC-1 and AsPC- 1 cells in a dose- and time-dependent manner (Figure $5 A, B, C, D$ ). Ellagic acid did not affect the MMP-2 and MMP-9 expression in MIA PaCA-2 cells (Figure 5E,F).

The Inhibitory effect of ellagic acid on TGF- $\beta$, MMP-2, and MMP-9 expression was confirmed by ELISA. The expression levels of TGF- $\beta$, MMP-2, and MMP-9 proteins in PANC-1 and AsPC-1 cells were decreased by ellagic acid in a dose-dependent manner (Figure 6A,B,C,D,E,F). TGF- $\beta$, MMP-2, and MMP-9 protein expression in MIA PaCA2 cells remained unchanged after ellagic acid treatment (Figure 6G,H,I).

The effect of ellagic acid on pancreatic cell migration was examined using Boyden chambers. Pancreatic cells were plated with $2 \%$ FBS on upper wells, and migration was induced by $10 \%$ FBS in lower wells. The migrated cells were counted. PANC-1 and AsPC-1 cell migration was inhibited when ellagic acid was present; however the migration of MIA PaCA-2 cell was not inhibited (Figure $7 A, B, C$ ).

\section{Discussion}

Ellagic acid has been shown to have an antiproliferative effect on pancreatic cancer cells both in vitro and in vivo used by PANC-1 $(14,22)$. In this report, two other pancreatic cancer cells were used. Proliferation of all three pancreatic cell lines, PANC-1, AsPC-1, and MIA PaCA-2, was inhibited by ellagic acid; however, the affected dose and 

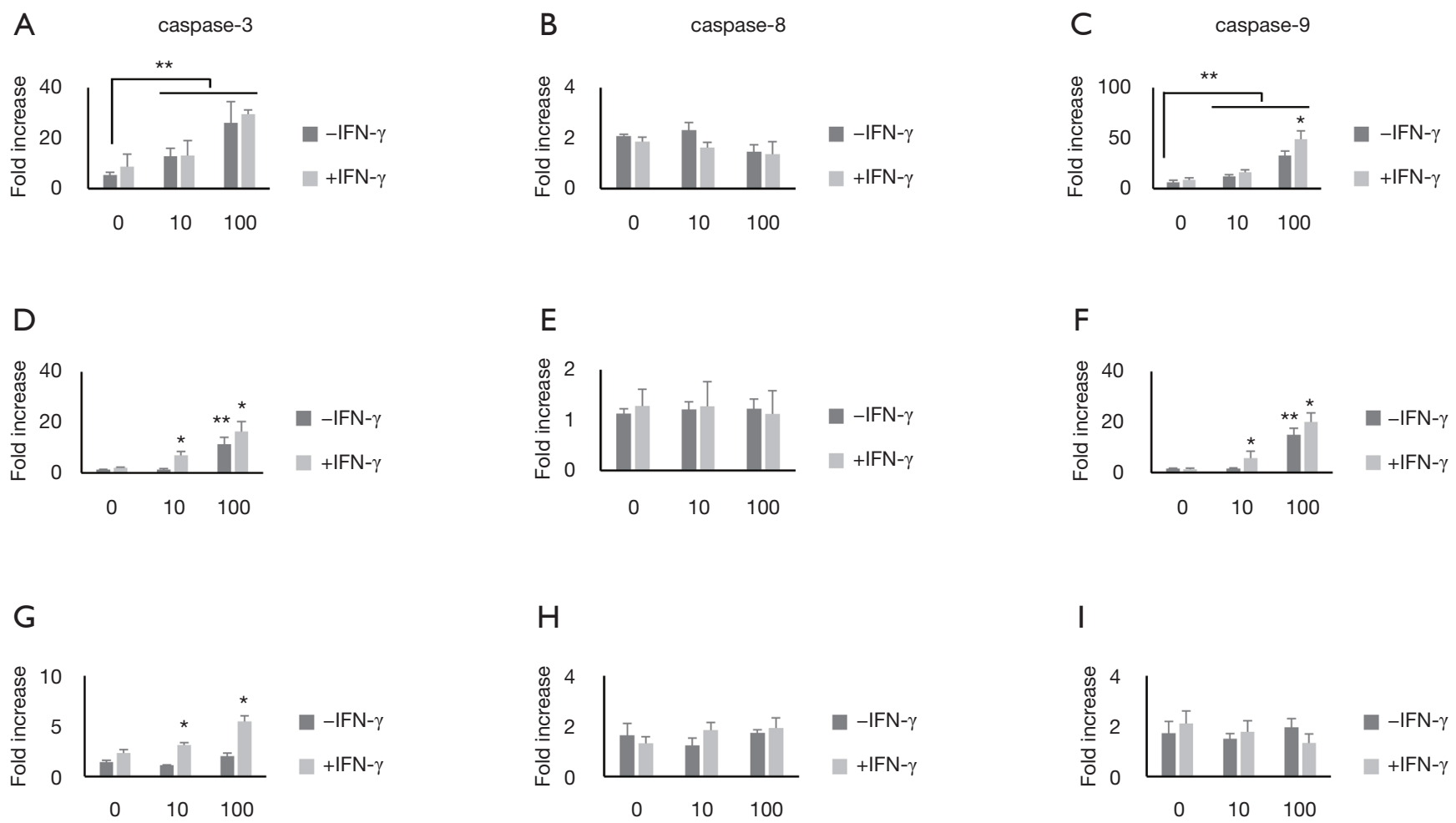

Figure 3 Ellagic acid inhibits caspase-3 and caspase-9 activity. (A,B,C) PANC-1, (D,E,F) AsPC-1, (G,H,I) MIA PaCA-2. Cells were plated on microplates with ellagic acid and incubated for 48 h. 0 to $1,000 \mu \mathrm{M}$ ellagic acid were treated on each cell with or without IFN- $\gamma$. Caspase activity was measured by caspase multiplex kit as following manufacture's protocol. Activity was calculated as the fold increasement for cells before ellagic acid treatment. Data are presented as mean $\pm \mathrm{SD}$ from three individual experiments. **, $\mathrm{P}<0.05$ compared with control group and IFN- $\gamma$ treatment group. *, $\mathrm{P}<0.05$ compared with $0 \mathrm{~h}$.

time were different for each cell (Figure 1). The reduction in cell growth of PANC-1 was observed when $10 \mu \mathrm{M}$ ellagic acid was added, but $1,000 \mu \mathrm{M}$ of ellagic acid was needed to reduce MIA PaCA-2 cell growth within $48 \mathrm{~h}$. AsPC-1 growth decreased within $48 \mathrm{~h}$ after adding $100 \mu \mathrm{M}$ ellagic acid. Taken together, PANC-1 is most sensitive, while MIA PaCA-2 is most resistant to ellagic acid. The effect of ellagic acid on a xenograft model of pancreatic cancer cells was not evaluated in this study. Further studies using different pancreatic cancer cell lines or patient- derived xenograft models are needed to verify the different effects of ellagic acid.

To determine the cause of growth reduction by ellagic acid, the activities of caspase- 3 , caspase- 8 , and caspase- 9 were measured. The caspase- 3 and caspase- 9 activities in PANC-1 and AsPC-1 cells increased after ellagic acid treatment, but the caspase- 8 activity did not affect cell growth. The caspase activity did not increase after ellagic acid treatment in the MIA PaCA-2 cells (Figure 3). Caspase activity was not detected in MIA PaCA-2 cells, which are not affected by ellagic acid. Caspase signaling is mediated by apoptosis, a type of programmed cell death, which is conducted in two pathways: the extrinsic pathway and the intrinsic pathway. The extrinsic pathway is mediated by caspase-8, and the intrinsic pathway can be initiated by caspase-9. Caspase- 3 is activated in both pathways and triggers apoptosis $(23,24)$. This finding suggests that the inhibition of pancreatic cancer cell growth by ellagic acid is caused by apoptosis and is triggered by the intrinsic pathway.

IFN- $\gamma$ has been reported to inhibit the proliferation of pancreatic cancer cells, including AsPC-1, Capan-1, Capan-2, and Dan-G cells, via caspase-1 dependent induction of apoptosis (25). IFN- $\gamma$ also promotes EMT in 
A
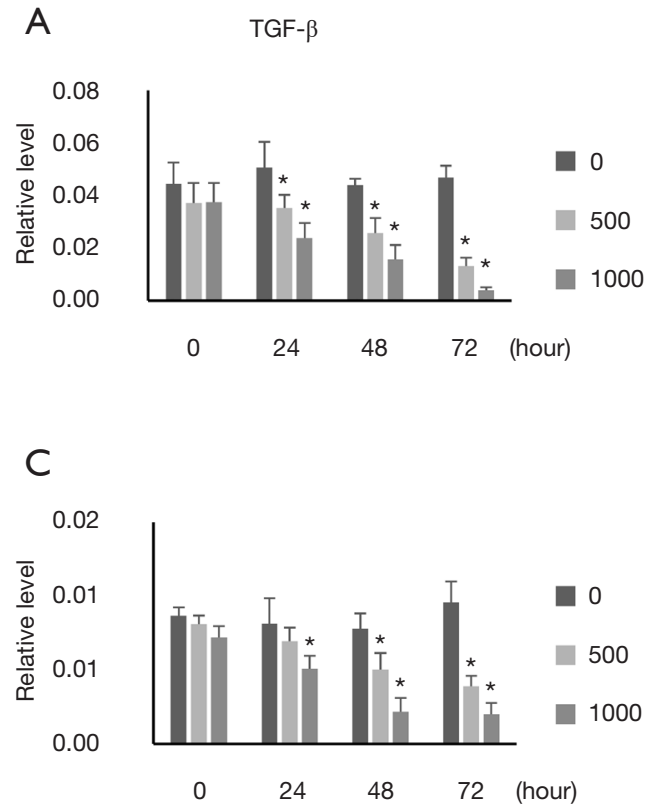

E

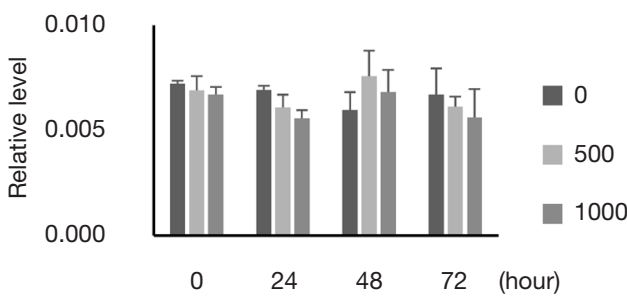

B

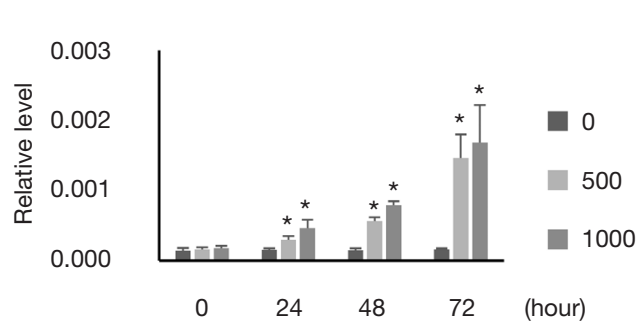

D

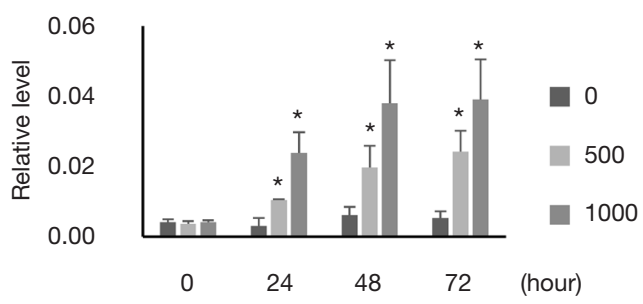

$\mathrm{F}$

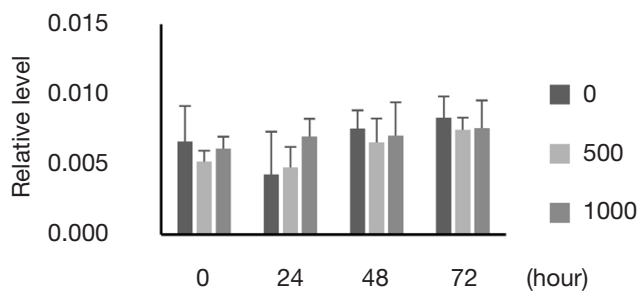

Figure 4 Ellagic acid inhibits TGF- $\beta$ mRNA expression and promotes E-cadherin mRNA expression. (A,B) PANC-1, (C,D) AsPC-1, (E,F) MIA PaCA-2. Cells were incubated with each indicated concentration ellagic acid for $72 \mathrm{~h}$. During incubation, cells were collected every $24 \mathrm{~h}$. RNA was isolated from cells and cDNA was synthesized from RNA. q-PCR was performed and relative expression of GAPDH were presented. (A,C,E) relative TGF-b expression of GAPDH. (B,D,F) relative E-cadherin expression of GAPDH. All data are presented as mean $\pm \mathrm{SD}$ from a minimum of three individual experiments. *, $\mathrm{P}<0.05$ compared with control.

pancreatic cells (26). In this study, the effect of ellagic acid on cell growth after IFN- $\gamma$ treatment was also examined. IFN- $\gamma$ inhibits the growth of all three different pancreatic cells, PANC-1, AsPC-1, and MIA PaCA-2. Ellagic acid further inhibited the growth of PANC-1 and AsPC-1, but not the growth of MIA PaCA-2 after IFN- $\gamma$ treatment (Figure 2). However, caspase-3 and caspase-9 activities were not further increased by ellagic acid and IFN- $\gamma$ treatment in PANC-1 cells. AsPC-1 and MIA PaCA-2 cells have further increased the activity of caspase- 3 by ellagic acid and IFN- $\gamma$ treatment, but this effect was small. The absence of changes in proliferation after IFN- $\gamma$ treatment did not increase the severity of apoptosis.

Ellagic acid blocks the effects of proinflammatory agents and mainly inhibits the expression of cyclooxygenase 2 (COX-2) and nuclear factor-kappa B (NF- $\mathrm{B}$ ) in several types of cells, including pancreatic cancer cells $(1,14,22)$. E-cadherin expression increases because of the presence of ellagic acid in pancreatic cancer cells (22). The expression of MMP-2, MMP-9, and TGF- $\alpha$ decreased because of the presence of ellagic acid in hepatocytes and breast cancer cells $(27,28)$. Thus, we hypothesized that ellagic acid may inhibits migration of pancreatic cancer cells. To confirm this, the levels of TGF- $\beta$, E-cadherin, MMP-2, MMP-9 

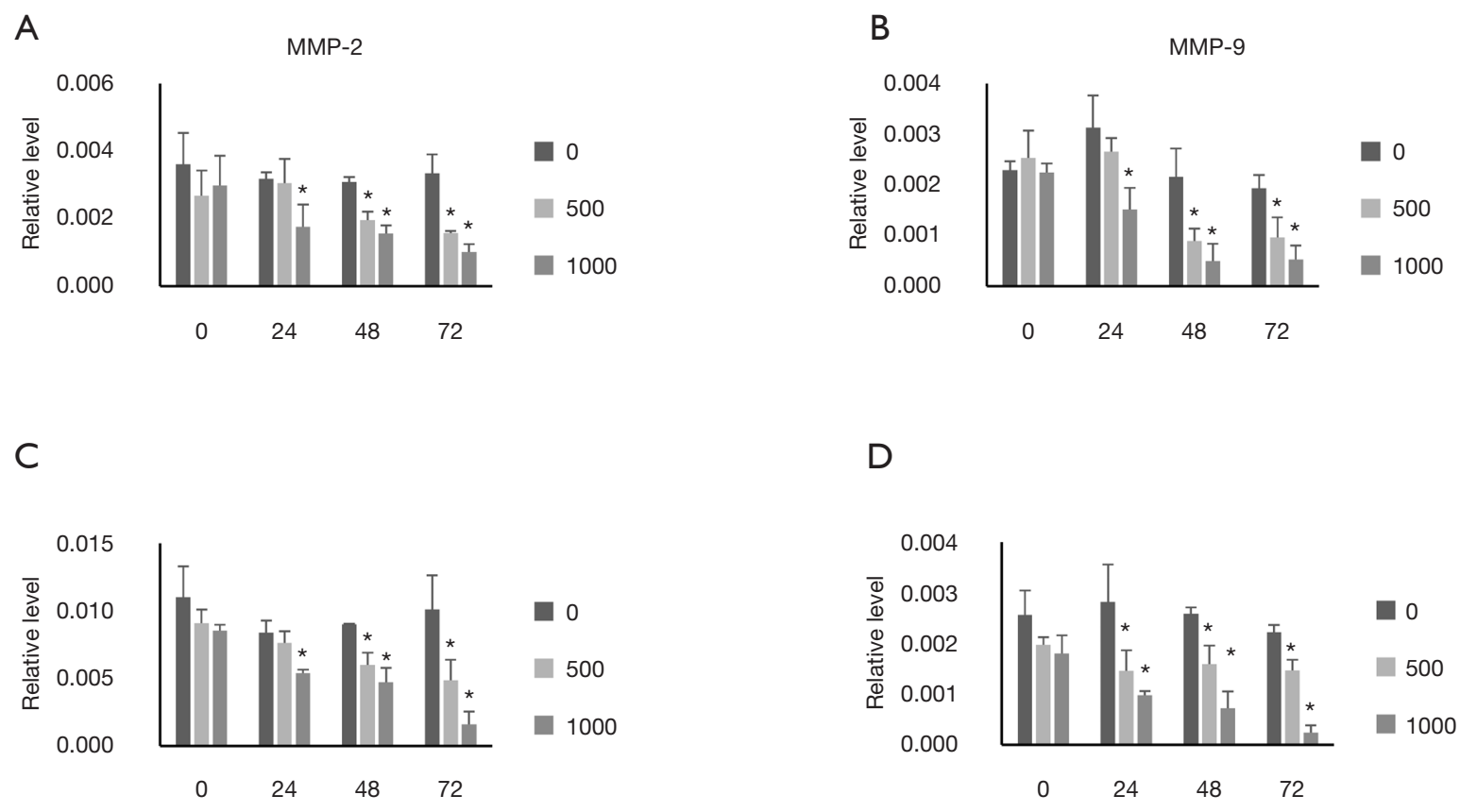

$E$

$\mathrm{F}$
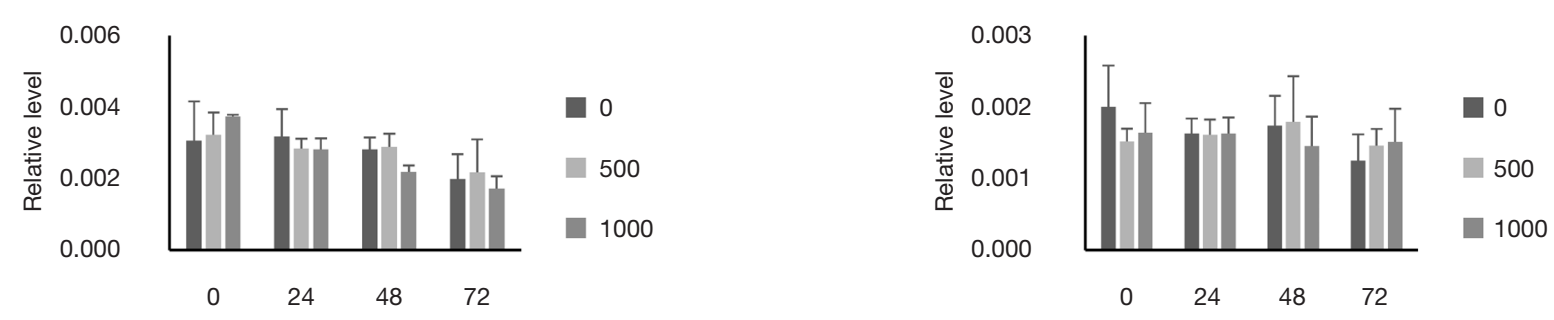

Figure 5 Ellagic acid inhibits MMP-2 and MMP-9 mRNA expression. (A,B) PANC-1, (C,D) AsPC-1, (E,F) MIA PaCA-2. Cells were incubated with each indicated concentration ellagic acid for $72 \mathrm{~h}$. During incubation, cells were collected every 24 h. RNA was isolated from cells and cDNA was synthesized from RNA. q-PCR was performed and relative expression of GAPDH were presented. (A,C,E) relative MMP-2 expression of GAPDH. (B,D,F) relative MMP-9 expression of GAPDH. All data are presented as mean \pm SD from a minimum of three individual experiments. *, $\mathrm{P}<0.05$ compared with control.

mRNA, and protein expression were measured. All of these decreased in PANC-1 and AsPC-1 cells, but not in MIA PaCA-2 cells. The concentration of ellagic acid decreased in a dose- and time-dependent manner (Figures 4-6). Ellagic acid also inhibits the migration of PANC-1 and AsPC-1 cells, but not the migration of MIA PaCA-2 cells. Taken together, ellagic acid may suppress EMT in pancreatic cells.

The effect of ellagic acid on proliferation and migration of pancreatic cancer cells was examined in this study. Ellagic acid inhibits proliferation and migration of pancreatic cancer cells. Inhibition of proliferation is caused by increased apoptosis. Ellagic acid-induced apoptosis occurs in the caspase- 3 and caspase- 9 pathways, but not in the caspase- 8 pathway. Inhibition of migration occurs with the decrease in E-cadherin and decrease in TGF- $\beta$, MMP-2, and MMP-9 levels. This effect of ellagic acid is only observed in PANC-1 and AsPC-2 cells, but not in MIA PaCA-2 cells. These results suggest that ellagic acid may inhibit pancreatic cancer, but it is dependent on the characteristics of cancer cells. 
A

TGF- $\beta$

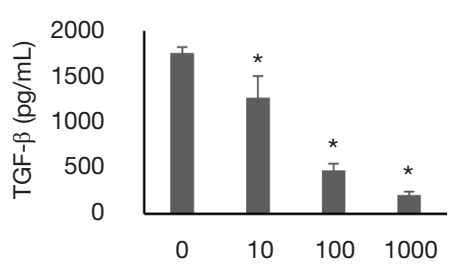

D

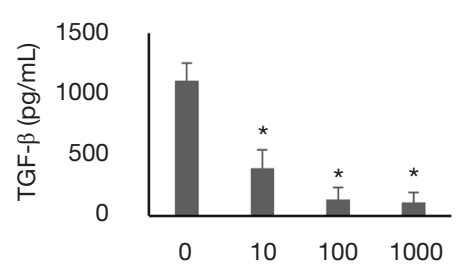

G

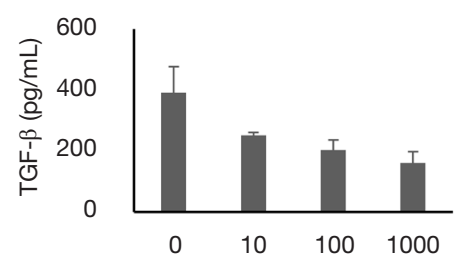

B

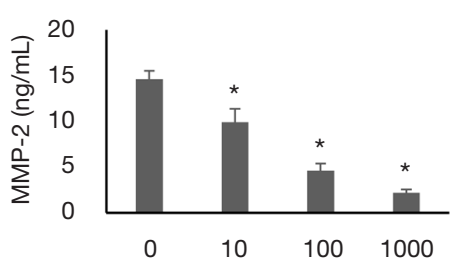

E

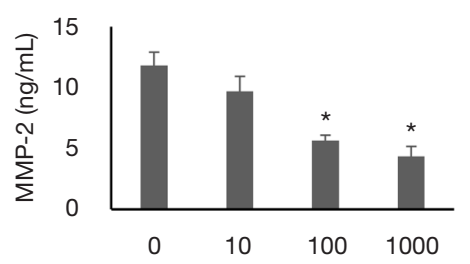

$\mathrm{H}$

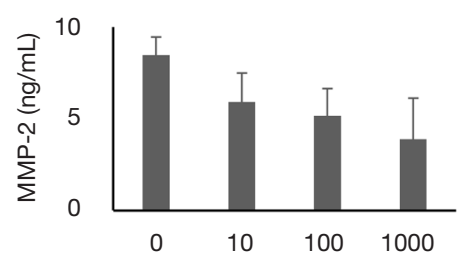

C

MMP-9

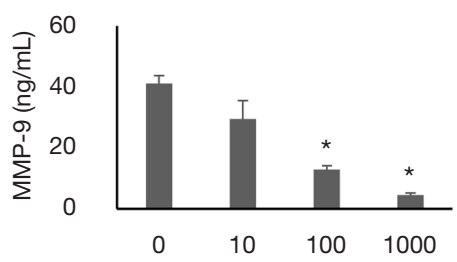

$\mathrm{F}$

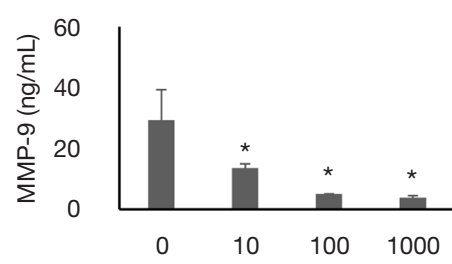

I

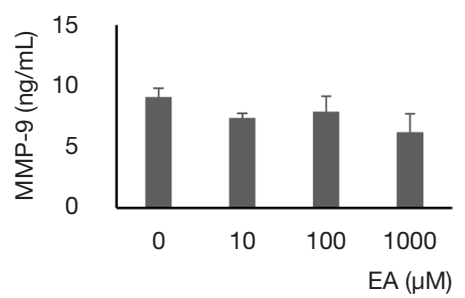

Figure 6 Ellagic acid inhibits TGF-b, MMP-2 and MMP-9 protein expression. (A,B,C) PANC-1, (D,E,F) AsPC-1, (G,H,I) MIA PaCA-2. Cells were incubated with each indicated concentration ellagic acid for $48 \mathrm{~h}$. Cell supernatant was collected and ELISA assay was performed. $(\mathrm{A}, \mathrm{D}, \mathrm{G}) \mathrm{TGF}-\beta$. (B,E,H) MMP-2. (C,F,I) MMP-9. All data are presented as mean \pm SD from a minimum of three individual experiments. *, $\mathrm{P}<0.05$ compared with control.
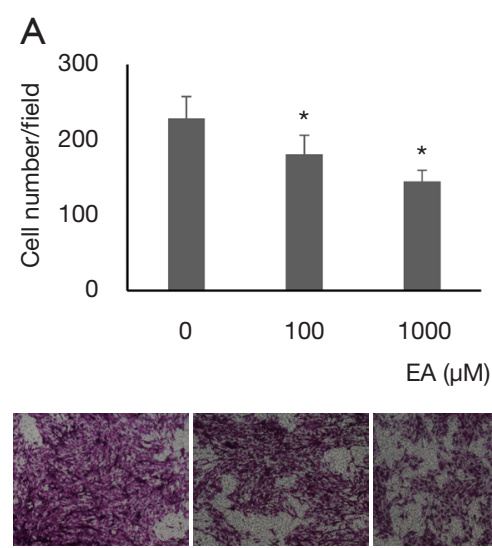

B
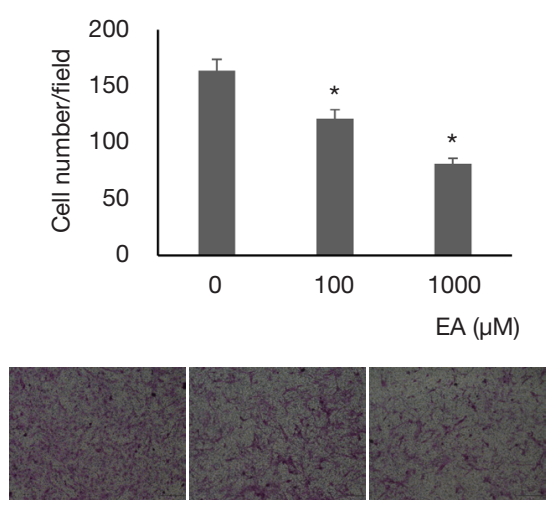

C
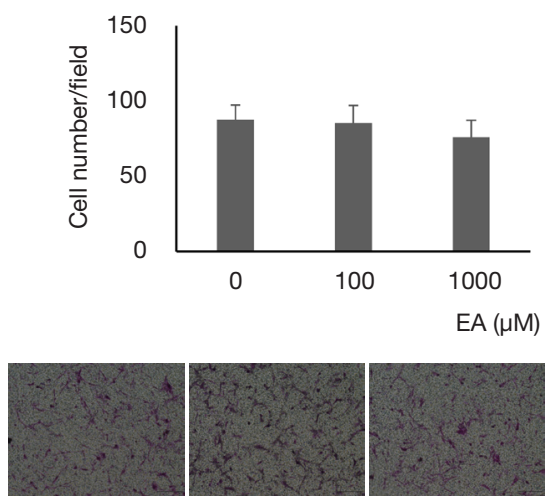

Figure 7 Ellagic acid inhibits migration of pancreatic cancer cells. (A) PANC-1, (B) AsPC-1, (C) MIA PaCA-2. Cells were plated on upper chamber, and incubated for $16 \mathrm{~h}$. indicated times. After remove unmigrated cells on upper chamber, migrated cells were fixed and stained with crystal violet. Cell number in high-power field were counted and presented. Data are presented as mean \pm SD from three individual experiments. *, $\mathrm{P}<0.05$ compared with control. Microscopic images were also presented. Scale bar: $200 \mathrm{~mm}$. 


\section{Acknowledgments}

Funding: This work was supported by Biomedical Research Institute grant, Kyungpook National University Hospital (2016).

\section{Footnote}

Reporting Checklist: The authors have completed the MDAR checklist. Available at http://dx.doi.org/10.21037/tcr-202446

Data Sharing Statement: Available at http://dx.doi. org/10.21037/tcr-20-2446

Conflicts of Interest: All authors have completed the ICMJE uniform disclosure form (available at http://dx.doi. org/10.21037/tcr-20-2446). The authors have no conflicts of interest to declare.

Ethical Statement: The authors are accountable for all aspects of the work in ensuring that questions related to the accuracy or integrity of any part of the work are appropriately investigated and resolved. The study was conducted in accordance with the Declaration of Helsinki (as revised in 2013).

Open Access Statement: This is an Open Access article distributed in accordance with the Creative Commons Attribution-NonCommercial-NoDerivs 4.0 International License (CC BY-NC-ND 4.0), which permits the noncommercial replication and distribution of the article with the strict proviso that no changes or edits are made and the original work is properly cited (including links to both the formal publication through the relevant DOI and the license). See: https://creativecommons.org/licenses/by-nc-nd/4.0/.

\section{References}

1. Garcia-Nino WR, Zazueta C. Ellagic acid: Pharmacological activities and molecular mechanisms involved in liver protection. Pharmacol Res 2015;97:84-103.

2. Thresiamma KC, Kuttan R. Inhibition of liver fibrosis by ellagic acid. Indian J Physiol Pharmacol 1996;40:363-6.

3. Stoner GD, Gupta A. Etiology and chemoprevention of esophageal squamous cell carcinoma. Carcinogenesis 2001;22:1737-46.

4. Han DH, Lee MJ, Kim JH. Antioxidant and apoptosis- inducing activities of ellagic acid. Anticancer Res 2006;26:3601-6.

5. Mandrekar P, Szabo G. Signalling pathways in alcoholinduced liver inflammation. J Hepatol 2009;50:1258-66.

6. Siegmund SV, Brenner DA. Molecular pathogenesis of alcohol-induced hepatic fibrosis. Alcohol Clin Exp Res 2005;29:102S-9S.

7. Das J, Ghosh J, Roy A, et al. Mangiferin exerts hepatoprotective activity against $\mathrm{D}$-galactosamine induced acute toxicity and oxidative/nitrosative stress via Nrf2-NFkappaB pathways. Toxicol Appl Pharmacol 2012;260:35-47.

8. El-Shitany NA, El-Bastawissy EA, El-desoky K. Ellagic acid protects against carrageenan-induced acute inflammation through inhibition of nuclear factor kappa B, inducible cyclooxygenase and proinflammatory cytokines and enhancement of interleukin-10 via an antioxidant mechanism. Int Immunopharmacol 2014;19:290-9.

9. Cornelio Favarin D, Martins Teixeira M, Lemos de Andrade E, et al. Anti-inflammatory effects of ellagic acid on acute lung injury induced by acid in mice. Mediators Inflamm 2013;2013:164202.

10. Mukhtar H, Das M, Khan WA, et al. Exceptional activity of tannic acid among naturally occurring plant phenols in protecting against 7,12-dimethylbenz(a)anthracene-, benzo(a)pyrene-, 3-methylcholanthrene-, and N-methyl$\mathrm{N}$-nitrosourea-induced skin tumorigenesis in mice. Cancer Res 1988;48:2361-5.

11. Larrosa M, Gonzalez-Sarrias A, Garcia-Conesa MT, et al. Urolithins, ellagic acid-derived metabolites produced by human colonic microflora, exhibit estrogenic and antiestrogenic activities. J Agric Food Chem 2006;54:1611-20.

12. Bell C, Hawthorne S. Ellagic acid, pomegranate and prostate cancer -- a mini review. J Pharm Pharmacol 2008;60:139-44.

13. Strati A, Papoutsi Z, Lianidou E, et al. Effect of ellagic acid on the expression of human telomerase reverse transcriptase (hTERT) alpha+beta+ transcript in estrogen receptor-positive MCF-7 breast cancer cells. Clin Biochem 2009;42:1358-62.

14. Edderkaoui M, Odinokova I, Ohno I, et al. Ellagic acid induces apoptosis through inhibition of nuclear factor kappa B in pancreatic cancer cells. World J Gastroenterol 2008;14:3672-80.

15. Chung YC, Lu LC, Tsai MH, et al. The inhibitory effect of ellagic Acid on cell growth of ovarian carcinoma cells. Evid Based Complement Alternat Med 2013;2013:306705. 
16. Umesalma S, Sudhandiran G. Ellagic acid prevents rat colon carcinogenesis induced by 1,2 dimethyl hydrazine through inhibition of AKT-phosphoinositide-3 kinase pathway. Eur J Pharmacol 2011;660:249-58.

17. Srigopalram S, Jayraaj IA, Kaleeswaran B, et al. Ellagic acid normalizes mitochondrial outer membrane permeabilization and attenuates inflammation-mediated cell proliferation in experimental liver cancer. Appl Biochem Biotechnol 2014;173:2254-66.

18. Siegel RL, Miller KD, Jemal A. Cancer Statistics, 2017. CA Cancer J Clin 2017;67:7-30.

19. Saad AM, Turk T, Al-Husseini MJ, et al. Trends in pancreatic adenocarcinoma incidence and mortality in the United States in the last four decades; a SEER-based study. BMC Cancer 2018;18:688.

20. Quail DF, Joyce JA. Microenvironmental regulation of tumor progression and metastasis. Nat Med 2013;19:1423-37.

21. Westphal S, Kalthoff H. Apoptosis: targets in pancreatic cancer. Mol Cancer 2003;2:6.

22. Cheng H, Lu C, Tang R, et al. Ellagic acid inhibits the proliferation of human pancreatic carcinoma PANC-1 cells in vitro and in vivo. Oncotarget 2017;8:12301-10.

23. Fulda S, Debatin KM. Extrinsic versus intrinsic apoptosis pathways in anticancer chemotherapy. Oncogene 2006;25:4798-811.

24. Carneiro BA, El-Deiry WS. Targeting apoptosis in cancer therapy. Nat Rev Clin Oncol 2020;17:395-417.

25. Detjen KM, Farwig K, Welzel M, et al. Interferon gamma inhibits growth of human pancreatic carcinoma cells via caspase-1 dependent induction of apoptosis. Gut 2001;49:251-62.

26. Imai D, Yoshizumi T, Okano S, et al. IFN-gamma Promotes Epithelial-Mesenchymal Transition and the Expression of PD-L1 in Pancreatic Cancer. J Surg Res 2019;240:115-23.

27. Devipriya N, Sudheer AR, Srinivasan M, et al. Effect of Ellagic Acid, a Plant Polyphenol, on Fibrotic Markers (MMPs and TIMPs) during Alcohol-Induced Hepatotoxicity. Toxicol Mech Methods 2007;17:349-56.

28. Zhang T, Chen HS, Wang LF, et al. Ellagic acid exerts anti-proliferation effects via modulation of Tgf-beta/ Smad3 signaling in MCF-7 breast cancer cells. Asian Pac J Cancer Prev 2014;15:273-6.
Cite this article as: Kim JY, Choi YJ, Kim HJ. Determining the effect of ellagic acid on the proliferation and migration of pancreatic cancer cell lines. Transl Cancer Res 2021;10(1):424-433. doi: $10.21037 /$ tcr-20-2446 